\title{
Novel chicken two-dimensional intestinal model comprising all key epithelial cell types and a mesenchymal sub-layer
}

Brigid Orr ${ }^{1}$, Kate Sutton ${ }^{1}$, Sonja Christian², Tessa Nash', Helle Niemann², Lone Lind Hansen², Mike J. McGrew', Stina Rikke Jensen ${ }^{2}$ and Lonneke Vervelde ${ }^{{ }^{* *}}$ (D)

\begin{abstract}
The intestinal epithelium plays a variety of roles including providing an effective physical barrier and innate immune protection against infection. Two-dimensional models of the intestinal epithelium, $2 \mathrm{D}$ enteroids, are a valuable resource to investigate intestinal cell biology and innate immune functions and are suitable for high throughput studies of paracellular transport and epithelial integrity. We have developed a chicken 2D enteroid model that recapitulates all major differentiated cell lineages, including enterocytes, Paneth cells, Goblet cells, enteroendocrine cells and leukocytes, and self-organises into an epithelial and mesenchymal sub-layer. Functional studies demonstrated the 2D enteroids formed a tight cell layer with minimal paracellular flux and a robust epithelial integrity, which was maintained or rescued following damage. The 2D enteroids were also able to demonstrate appropriate innate immune responses following exposure to bacterial endotoxins, from Salmonella enterica serotype Typhimurium and Bacillus subtilis. Frozen 2D enteroids cells when thawed were comparable to freshly isolated cells. The chicken 2D enteroids provide a useful ex vivo model to study intestinal cell biology and innate immune function, and have potential uses in screening of nutritional supplements, pharmaceuticals, and bioactive compounds.
\end{abstract}

Keywords: Chicken, Intestinal epithelium, 2D enteroid, Organoid, Barrier integrity, Immune response, Bacteria, Gut model

\section{Introduction}

The small intestine is a highly complex structure with several roles; in addition to nutrient and water absorption from ingested food and secretion of digestive enzymes it acts as physiological barrier, prevents invasion of commensal and pathogenic bacteria in the lumen and regulates the intestinal immune system. An inner folded single layer of endodermal epithelial cells with crypts and villi is exposed to the lumen [1] and beneath the epithelium lies the layered mesenchymal cell architecture of the

\footnotetext{
*Correspondence: Lonneke.vervelde@roslin.ed.ac.uk

${ }^{1}$ Division of Infection and Immunity, The Roslin Institute and Royal

(Dick) School of Veterinary Studies, University of Edinburgh, Edinburgh, Midlothian, UK

Full list of author information is available at the end of the article
}

supportive lamina propria [2]. Homeostasis of the intestine and responses to disease are coordinated by an interplay between the epithelial cells, mesenchymal cells and immune cells through cell-cell contact or soluble factors $[1,2]$.

To study the intestine ex vivo, three-dimensional (3D) intestinal organoids have been developed in several mammalian species from adult stem cells or isolated crypts and villi including human $[3,4]$ mouse $[4,5]$, pig [6], cow [7], and horse [8]. However, the inner lumen of these 3D organoids provide limited access to the apical epithelial surface and experiments often require time-consuming microinjections. Therefore, researchers have generated two-dimensional (2D) polarised models of intestinal monolayers to allow access to the original author(s) and the source, provide a link to the Creative Commons licence, and indicate if changes were made. The images or other third party material in this article are included in the article's Creative Commons licence, unless indicated otherwise in a credit line to the material. If material is not included in the article's Creative Commons licence and your intended use is not permitted by statutory regulation or exceeds the permitted use, you will need to obtain permission directly from the copyright holder. To view a copy of this licence, visit http://creativecommons.org/licenses/by/4.0/. The Creative Commons Public Domain Dedication waiver (http://creativeco mmons.org/publicdomain/zero/1.0/) applies to the data made available in this article, unless otherwise stated in a credit line to the data. 
apical side of the cells and measure effects on the epithelial barrier in a standardised way. Successful intestinal monolayers have subsequently been developed in many of these species; human $[9,10]$, mouse $[9,11$, 12], pig [13], cow [14], and cat [15]. For poultry, 2D and $3 \mathrm{D}$ ex vivo models of the chicken intestine have been described [16-27]. However, there are currently no chicken intestinal monolayer models that demonstrate expression of all epithelial cell types and form a confluent cell layer with robust epithelial integrity, that can be used to study paracellular permeability and barrier function.

Chickens are precocial birds and by late embryonic development their intestines have formed mature functional epithelial cells in the villi but with only rudimentary crypt structures $[28,29]$. The epithelial cells originate from stem cells, but in contrast to mammals, almost all villus cells in poultry are proliferative at hatch with cell mitosis playing an important role in post-hatch hyperplasia $[18,29]$. The epithelial layer is made up of absorptive enterocytes, mucin-secreting goblet cells and enteroendocrine cells, Paneth cells and stem cells $[25,30]$.

Recently, we developed a method for generating 3D outward facing avian enteroids [25], which allows for direct manipulation and access to apical surface of the epithelium, without the need for micro injection. However, due to the 3D structure it is not suitable for automated Trans Epithelial Electrical Resistance (TEER) measurements; TEER is a real-time, non-destructive, label free method to measure epithelial integrity. Existing in vitro chicken $2 \mathrm{D}$ enteroids models $[18,24]$ lacked the ability to form tight confluent cell layers and are limited in their use to study epithelial integrity and permeability. Here, we present an optimised protocol to generate chicken $2 \mathrm{D}$ enteroids that contain all major differentiated epithelial cell lineages and a self-organised sub-epithelial mesenchymal layer.

\section{Materials and methods \\ Animals}

Experiments were performed using embryonic day (ED18) Hy-Line Brown chickens (Gallus gallus) obtained from the National Avian Research Facility, Edinburgh, UK or Lohmann-LSL-LITE Layers from Lohmann, Denmark. Ethical approval was obtained from the Roslin Institute's and University of Edinburgh Animal Welfare Ethics Review Board. The experiments were performed under the authority of UK Home Office Licenses (PE263A4FA) in accordance within the guidelines and regulations of the UK Home Office "Animals (scientific procedures Act 1986)".

\section{Tissue isolation and enteroid culture}

Tissue was isolated as previously described [25]. In brief, freshly removed chicken intestine (duodenum, jejunum, ileum and caeca) from ED18 Hy-Line Brown embryos was cut open longitudinally and then transversely into $5 \mathrm{~mm}$ pieces. The tissues were washed in Hank's Buffered Saline Solution [14170595, Thermofisher Scientific, Paisley, UK (TFS)] and digested using collagenase from Clostridium histolyticum type IA $(0.2 \mathrm{mg} / \mathrm{mL}$, Merck, Gillingham, UK) in DMEM (D5796, TFS) at $37{ }^{\circ} \mathrm{C}$ for $50 \mathrm{~min}$ with shaking at $200 \mathrm{rpm}$. Then, after vigorous shaking by hand for $1 \mathrm{~min}$, the release of the villi was checked using an inverted microscope. The larger pieces of tissue settled by gravity and fractions of villi in suspension were collected by filtering the digestion solution over a $70 \mu \mathrm{M}$ strainer, (CLS231751, Corning, Loughborough, UK), inverting the strainer and washing out the villi with phosphate buffered saline (PBS) into a petri dish. Then, the fractions containing the villi were pooled and pelleted at $100 \times g$ for $4 \mathrm{~min}$. Aliquots of each fraction were checked for purity using an inverted microscope. Cell pellets were resuspended in accutase (A1110501, TFS) and incubated for $5 \mathrm{~min}$ at $37^{\circ} \mathrm{C}$, mechanically disrupted by pipetting and further incubated for $5 \mathrm{~min}$ at $37^{\circ} \mathrm{C}$. Successful cell dissociation of epithelial and mesenchymal cells was checked and accutase activity was diluted in the cell suspension with 2 volumes of Advanced DMEM/ F12 (12634010, TFS) and filtered twice through a $40 \mu \mathrm{M}$ strainer (CLS431750, Corning) to eliminate cell aggregates. Cells were collected by centrifugation at $200 \times g$ for $4 \mathrm{~min}$. Cells were resuspended in Seeding Media (Table 1) and incubated for $3 \mathrm{~h}$ at $37{ }^{\circ} \mathrm{C}, 5 \% \mathrm{CO}_{2}$ in a 12-well plate to allow for preferential mesenchymal cell adherence. The single cell mix of epithelial cells and non-adherent mesenchymal cells was then used to seed the $2 \mathrm{D}$ enteroids (day 0) on 96-well plates or apical inserts of 24-well transwells (CLS-3396, Corning), coated with growth factor reduced Matrigel (354230, Corning; protein concentration $\sim 10 \mathrm{mg} / \mathrm{mL}$ 1:50 diluted in Basal Media), which had previously been allowed to polymerise for $1 \mathrm{~h}$ at $37^{\circ} \mathrm{C}$. Prior to seeding of the cells, excess Matrigel was removed from the wells and immediately replaced with Seeding media (Table 1). Cells were seeded at $1 \times 10^{5}$ using freshly isolated cells or $1-2 \times 10^{5}$ cells from the frozen cell stocks in Seeding Media (Table 1). For transwells, a total of $200 \mu \mathrm{L}$ of media/well was added to the apical compartment and $500 \mu \mathrm{L}$ of media was added to basal compartment. After $24 \mathrm{~h}$, cells were washed in Basal Media, and cultured with Maintenance Media, which was replaced every 2 days. Cells were incubated at $37{ }^{\circ} \mathrm{C}, 5 \% \mathrm{CO}_{2}$.

Cell culture images were captured on a Nikon TE300 microscope camera and Zen (Black) software (Zeiss, Jena, Germany). 
Table 1 List of reagents used to prepare cell culture media.

\begin{tabular}{|c|c|c|c|}
\hline Reagent & Concentration & Cat. No & Supplier \\
\hline \multicolumn{4}{|l|}{ Basal media } \\
\hline Advanced DMEM/F12 & $1 \times$ & 12634010 & ThermoFisher scientific (TFS) \\
\hline L-glutamine & $2 \mathrm{mM}$ & 25030024 & TFS \\
\hline HEPES & $10 \mathrm{mM}$ & 15630080 & TFS \\
\hline Penicillin/streptomycin & $50 \mathrm{U} / \mathrm{mL}$ & TFS & 15140122 \\
\hline \multicolumn{4}{|l|}{ Seeding media } \\
\hline Basal media & $1 \times$ & & \\
\hline B27 supplement & $1 \times$ & 17504044 & TFS \\
\hline N2 supplement & $1 \times$ & 17502048 & TFS \\
\hline EGF (human) & $100 \mathrm{ng} / \mathrm{mL}$ & PHG6045 & TFS \\
\hline LDN 193189 & $100 \mathrm{nM}$ & BV-2092-5 & Cambridge bioscience \\
\hline R-Spondin (human) & $100 \mathrm{ng} / \mathrm{mL}$ & $4645-R S$ & R\&D systems \\
\hline CHIR 99021 & $10 \mu \mathrm{M}$ & S1263-SEL & Stratech scientific \\
\hline Y27632 & $10 \mu \mathrm{M}$ & 72304 & Stem cell technologies \\
\hline \multicolumn{4}{|l|}{ Maintenance media } \\
\hline Basal media & $1 \times$ & & \\
\hline B27 supplement & $1 \times$ & & \\
\hline N2 supplement & $1 \times$ & & \\
\hline EGF (human) & $100 \mathrm{ng} / \mathrm{mL}$ & & \\
\hline Noggin (human) & $50 \mathrm{ng} / \mathrm{mL}$ & 6057_NG_025 & R\&D systems \\
\hline R-Spondin (human) & $100 \mathrm{ng} / \mathrm{mL}$ & & \\
\hline
\end{tabular}

\section{Immunofluorescence}

Confluent cell layers in 96-well plates or 24-well transwell membrane inserts were gently washed with PBS, fixed in $4 \%$ paraformaldehyde (PFA; 15670799 , TFS) for 10 or 20 min respectively and washed again with PBS. Cells in 96-well plates were permeabilised with $0.1 \%$ saponin (84510, Sigma, Gillingham, UK)/0.5\% bovine serum albumin (BSA; A2153, Sigma)/PBS or $0.1 \%$ Triton-X100 (Triton-X, Sigma)/0.5\% BSA/PBS for $10 \mathrm{~min}$ at RT and blocked with $5 \%$ goat serum in permeabilisation buffer for $1 \mathrm{~h}$ at RT. Cells were incubated overnight at $4{ }^{\circ} \mathrm{C}$ with primary antibodies diluted in blocking buffer, followed by species-specific secondary antibodies $(2 \mathrm{mg} / \mathrm{mL})$ or isotype controls diluted in permeabilisation buffer and incubated for $1 \mathrm{~h}$ at RT.

Cells on transwell membrane inserts were permeabilised with $0.5 \%$ Triton X/PBS for $10 \mathrm{~min}$ at RT and blocked with blocking buffer $10 \%$ goat serum $/ 0.1 \%$ Triton-X/PBS. Primary antibodies were diluted in $0.1 \%$ Triton-X/2\% BSA/PBS and incubated with cells for $1 \mathrm{~h}$ at RT. Antibodies were visualised with species and isotype specific secondary antibodies and phalloidin rhodamine diluted in in $0.1 \%$ Triton-X/2\% BSA/PBS and incubated for $15 \mathrm{~min}$ at RT. Primary and secondary antibodies are listed in Table 2.

For immunolocalisation of the subepithelial basal mesenchymal cells, prior to fixation, cells were incubated in
$1 \mathrm{mM}$ EDTA/0.5\% Triton-X/PBS for $20 \mathrm{~min}$ and flushed with PBS for removal of apical epithelial cells using a pastette. Control samples were incubated with isotype controls or secondary antibodies only. Nuclei were visualised with 4',6-diamidino-2-phenylindole (D9542, DAPI; Sigma). Transwell membrane inserts were removed for mounting in ProLong Diamond Antifade Mountant (P36965, TFS).

Fluorescent images on cell culture plates and thawed mesenchymal cell layer were captured using an Axiovert 25 microscope with Axiocam 503 colour camera (Zeiss) and Zen (Black) software (Zeiss). Mounted transwells were imaged using an Olympus 3000 inverted laser scanning microscopy with the PLAPON 60XOSC objective lens. Software acquisition and analysis was performed using FV31S-SW and cellSens software (Olympus, Tokyo, Japan).

\section{Measurement of permeability of 2D enteroids}

To measure permeability to small molecules, 2D enteroids on matrigel coated transwells were apically treated with $0.5 \mathrm{mg} / \mathrm{mL} 4 \mathrm{kDa}$ FITC-dextran (FD40S, Sigma) and at $0.5,1,2,3,4 \mathrm{~h}$ post application, $50 \mu \mathrm{L}$ of basal media was removed, and fluorescence measured on a Clariostar plate reader (BMG Labtech, Aylesbury, UK) with $490 \mathrm{~nm}$ excitation and $530 \mathrm{~nm}$ emission. At each time point, fluorescence measurements were taken in duplicate from 
Table 2 List of primary and secondary antibodies used for immunocytochemistry.

\begin{tabular}{|c|c|c|c|c|c|}
\hline Antibody & Antigen & Isotype & Cat no. & Supplier & Working dilution \\
\hline Mouse anti-chicken CD45 (clone AV53) & CD45 & $\lg G 1$ & $\mathrm{n} / \mathrm{a}$ & $\begin{array}{l}\text { Institute for Animal } \\
\text { Health, UK }\end{array}$ & 1:100 \\
\hline Rabbit anti bovine SP-1 Chromogranin A & Chromogranin A & $\lg G$ & 20085 & Immunostar & $1: 750$ \\
\hline Mouse anti-human E-cadherin (clone 36) & E-cadherin & $\lg G 2 a$ & 36/Ecadherin & BD Biosciences & $1: 50$ \\
\hline Phalloidin Rhodamine & F-actin & & R415 & Invitrogen & $1: 100$ \\
\hline Rabbit anti-chicken Lysozyme (polyclonal) & Lysozyme C & Poly lgG & Ab391 & Abcam & $1: 50$ \\
\hline Rabbit anti-human Muc5AC (clone 45M1) & Muc5AC & $\lg G 1$ & Ab212636 & Abcam & $1: 50$ \\
\hline Mouse anti-chicken Villin (clone 1D2C3) & Villin & $\lg G 1$ & Sc-58897 & Santa Cruz & $1: 50$ \\
\hline Mouse anti-pig Vimentin (clone V9) & Vimentin & $\lg G 1$ & Ab8069 & Abcam & $1: 50$ \\
\hline Rabbit anti-human ZO1 (polyclonal) & ZO1 & $\lg G$ & Ab216880 & Abcam & 1:100 \\
\hline Mouse anti-human ZO1 (clone A12) & ZO1 & $\lg G 1$ & $33-9100$ & Invitrogen & 1:100 \\
\hline Goat anti mouse Alexafluor ${ }^{\circledR} 488$ & Mouse lgG1 & $\lg G 1$ & A-21121 & Invitrogen & $1: 200$ \\
\hline Goat anti mouse Alexafluor ${ }^{\circledR} 488$ & Mouse lgG & $\lg G$ & A-11001 & Invitrogen & $1: 200$ \\
\hline Goat anti mouse Alexafluor ${ }^{\circledR} 546$ & Mouse lgG2a & $\lg G 2 a$ & A-21133 & Invitrogen & $1: 200$ \\
\hline Goat anti rabbit Alexafluor ${ }^{\circledR} 568$ & Rabbit lgG & $\lg G$ & A-11036 & Invitrogen & $1: 200$ \\
\hline Goat anti rabbit Alexafluor ${ }^{\circledR} 647$ & Rabbit lgG & $\lg G$ & A-21244 & Invitrogen & $1: 200$ \\
\hline
\end{tabular}

three wells containing cells, two coated wells with no cells and one well with media only. After each measurement, the media samples were returned to their original compartments. Fluorescence was normalised against the measurement of media only (no cells and no FITC-dextran) across all time points.

Trans epithelial electrical resistance (TEER) of 2D enteroids TEER was measured using an epithelial voltohmmeter (EVOM2, World Precision Instruments, Hitchin, UK) and chopstick electrode (STX2). In all experiments, the TEER of coated wells without cells was $\sim 16-30 \Omega \cdot \mathrm{cm}^{2}$. The final TEER value was calculated from the following equation, $T E E R=\left(R_{\text {cell layer }}-R_{\text {blank }}\right) \times A . R_{\text {cell layer }}$ is the resistance of the cell layer with the coated filter membrane; $R_{\text {blank }}$ is the resistance of the coated filter membrane without cells, and $\mathrm{A}$ is the surface area of the membrane $\left(0.33 \mathrm{~cm}^{2}\right)$. To compare between experiments, all wells were normalised to controls in the same experiment. Cells in 24-well transwells were cultured with $200 \mu \mathrm{L}$ apical and $500 \mu \mathrm{L}$ basal media. Media was replaced in the apical and basal compartments every 1-2 days. TEER readings were performed twice per well for duplicate wells from day 3 , when a confluent $2 \mathrm{D}$ enteroid with maximum TEER was formed.

\section{Manipulation of 2D enteroids with treatments or bacterial endotoxins}

For measurement of TEER, treatments were added to Maintenance Media or Low Calcium Media (LCM) in the apical and basal compartments in Matrigel-coated transwells. Treatments were added from day 3, when a confluent cell layer had formed and replaced every 2 days with Maintenance Media. On day 3 the cell layers were treated with 3-, 5-, or $7 \mathrm{mM}$ sodium butyrate (NaB; 303410, Sigma) or with 1.2-2 mM calcium chloride (99609, Sigma). Low calcium media was prepared by combining DMEM (no $\mathrm{Ca}^{2+} ; 21068028$, TFS) with Advanced DMEM/F12 (TFS) in appropriate ratios to make LCM containing $0.26 \mathrm{mM}$ calcium.

To measure the effect of pathogen challenge, the 2D enteroids were treated with heat-inactivated avian pathogenic Escherichia coli O1 serotype 01:K1:H7 (HiAPEC) (multiplicity of infection; MOI 1, 10, 100), Lipolysaccharide (LPS) from Salmonella enterica serotype Enteridis (S. Enteridis; L7770), Salmonella enterica serotype Typhimurium ( $S$. Typhimurium; L6143), Escherichia coli (E. coli 055:B5; L6529) or Lipoteichoic acid (LTA; L3265, all from Sigma) at $0.1,1$ or $10 \mu \mathrm{g} / \mathrm{mL}$. APEC O1-eGFP was grown and eGFP expression confirmed as previously described [31]. HiAPEC was prepared by calculation of $\mathrm{CFU} / \mathrm{mL}$ and subsequent heat inactivation at $56{ }^{\circ} \mathrm{C}$ for $24 \mathrm{~h}$; loss of replication was checked on agar plates in the absence of antibiotics.

For qRT-PCR analysis, small intestines were pooled from five embryos and enteroids were prepared, as described earlier. Cells were seeded at $3 \times 10^{6}$ cells per well on non-coated 24-well plates in Seeding Media that was replaced with Maintenance Media after $24 \mathrm{~h}$ and on day 3 and 5 . On day 5 of culture, 2D enteroids were treated apically with or without 1 or $10 \mu \mathrm{g} / \mathrm{mL}$ of LPS from S. typhimurium or LTA from Bacillus subtilis (B. subtilis; Sigma) for $6 \mathrm{~h}$ at $37{ }^{\circ} \mathrm{C}, 5 \% \mathrm{CO}_{2}$. Cells were 
lysed with RLT buffer (Qiagen, Gillingham, UK) and stored at $-20{ }^{\circ} \mathrm{C}$ until use.

\section{Quantitative real-time polymerase chain reaction}

Total RNA was extracted using an RNeasy Plus Mini Kit with a gDNA column eliminator (74134, Qiagen) according to manufacturer's instructions. Reverse transcription was performed using the Superscript III First Strand Synthesis System (18080051, TFS) according to manufacturer's instructions using random hexamers and oligo (dT) 18 and $1 \mu \mathrm{g}$ of total RNA using G-STORM GS-1 thermal cycler (Gene Technologies, TFS). The cDNA samples were stored at $-20{ }^{\circ} \mathrm{C}$ until use. To measure mRNA levels, 1:5 dilution of cDNA was mixed with $10 \mu \mathrm{L}$ of ABI TaqMan Gene Expression Master Mix (4369016, Applied Biosystems, TFS), $1 \mu \mathrm{L}$ of 20X EvaGreen (31000, Biotum, VWR-Bie \& Berntsen, Lutterworth, UK) and specific primer pairs (forward and reverse) at a final concentration of $1.15 \mu \mathrm{M}$ for interleukin 6 (IL-6, F:GCTCGC CGGCTTCGA, R:GGTAGGTCTGAAAGGCGAACAG, Acc. No. AJ309540.1), IL-8L2 (CXCLi2, F:GCCCTCCTC CTGGTTTCAG, R:TGGCACCGCAGCTCATT, Acc. No. FNM_205498.1), $\alpha$ smooth muscle actin ( $\alpha$ SMA, F: TCTGGGCGTACTACAGGGAT, R: GCATGATGG CATGTGGCAAA, Acc. No. NM_001031229.1), Desmin (F:CGAGGAGAACCGGATCAGCA, R: TTCTTG GTGTGCACCTCGG Acc. No. XM_015290092.3) and housekeeping genes, glyceraldehyde phosphate dehydrogenase (GAPDH, F:GAAGGCTGGGGCTCATCTG, R:CAGTTGGTGGTGCACGATG, Acc. No. AF047874) and ribosomal 28S (r28S, F:GGCGAAGCCAGAGGA AACT, R: GACGACCGATTTGCACGTC, Acc. No. FM165415), as previously described [32]. Reactions were performed in triplicate and no template controls without cDNA were included to detect any potential non-specific amplification. Efficiency of each reaction was calculated based on serial tenfold dilutions of calibration sample. The qPCR reaction was carried out at $50{ }^{\circ} \mathrm{C}$ for $2 \mathrm{~min}$, $95{ }^{\circ} \mathrm{C}$ for $10 \mathrm{~min}$ followed by 40 cycles at $95{ }^{\circ} \mathrm{C}$ for $15 \mathrm{~s}$ and $60{ }^{\circ} \mathrm{C}$ for $1 \mathrm{~min}$. Data normalisation was based on the geometric mean of two reference genes, r28S and GAPDH. Relative quantities of IL-6 and CXCLi2 were calculated compared to the untreated control group. The expression of Lgr5, $\alpha$ SMA and desmin mRNA in 2D cultures was calculated using the corrected $40-\mathrm{Ct}$ method as previously described [33].

\section{Cryopreservation of enteroids}

To cryopreserve the isolated cells, non-adherent cells containing epithelial cells and some mesenchymal cells were pooled from wells after the adherence step and pelleted at $200 \times g$ for $4 \mathrm{~min}$ at RT. Media was removed and cells were resuspended in Cryostor CS10 cryopreservation medium (7930, Stem Cell Technologies, SCT, Cambridge, UK) containing $10 \mathrm{mM}$ Y27632 (72304, SCT), at $1 \times 10^{6}$ cells $/ \mathrm{mL}$. Cryovials were stored overnight in a Mr Frosty freezing container (5100-0001, TFS) at $-80{ }^{\circ} \mathrm{C}$, and then transferred to liquid nitrogen for long-term storage.

To resuscitate the cells, the cryovials were thawed briefly in a water bath at $37^{\circ} \mathrm{C}$. The cell suspension was transferred to $5 \times$ volume of DMEM/F12 and pelleted by centrifugation at $200 \times g$ for $4 \mathrm{~min}$ at $\mathrm{RT}$ and cultured as previously described. Cells were seeded at a concentration of $1-2 \times 10^{5}$ cells/well in 24-well transwells and CHIR99021 (S1263-SEL, Stratech Scientific, Ely, UK) was added in the Seeding or Maintenance Media until day 1 or day 3 , respectively.

\section{Statistical analysis}

Statistical analysis was performed using GraphPad Prism 8.00 (GraphPad, San Diego, USA). All data was analysed for normality and TEER data was analysed by One-Way ANOVA with post-hoc Dunnett multiple comparison. qRT-PCR data was analysed by non-parametric KruskalWallis test adjusted for post-hoc analysis. The probability level for significance was taken as $P \leq 0.05$.

\section{Results \\ Establishment of 2D enteroids culture system}

To establish a chicken 2D enteroid culture system, we plated dissociated single cells from villi isolated from the intestine of ED18 embryos in a cell culture medium containing the growth factors, EGF, Noggin, R-spondin, CHIR99021 and ROCK inhibitor. We observed the initial formation of epithelial islands after $24 \mathrm{~h}$ (Figures $1 \mathrm{~A}$ and $\mathrm{B})$. The islands expanded to generate a confluent layer of epithelial cells by 3 days (Figure 1C), with the characteristic polygonal shape and cobblestone appearance found in 2D enteroids, also present at 6 days of culture (Figures 1D and E). Cells were most successfully grown on Matrigel coated wells but could also be grown to form confluent layers on uncoated cell culture plastic (Figure 1F).

\section{Identification of multi-cell lineages in 2D cultures}

To further characterise these 2D enteroids, immunofluorescent imaging was performed. All major differentiated epithelial cell lineages were present in the cultures corresponding to those present in the intestine. Epithelial cells were identified by E-cadherin expression at the cell surface, marking adherens junctions, and cytoplasmic villin staining indicated the presence of mature absorptive enterocytes. Paneth cells were identified by lysozyme expression and Goblet cells by Muc5AC staining. Chromogranin A expression indicated the presence of entero-endocrine cells and $\mathrm{CD} 45^{+}$leukocytes 


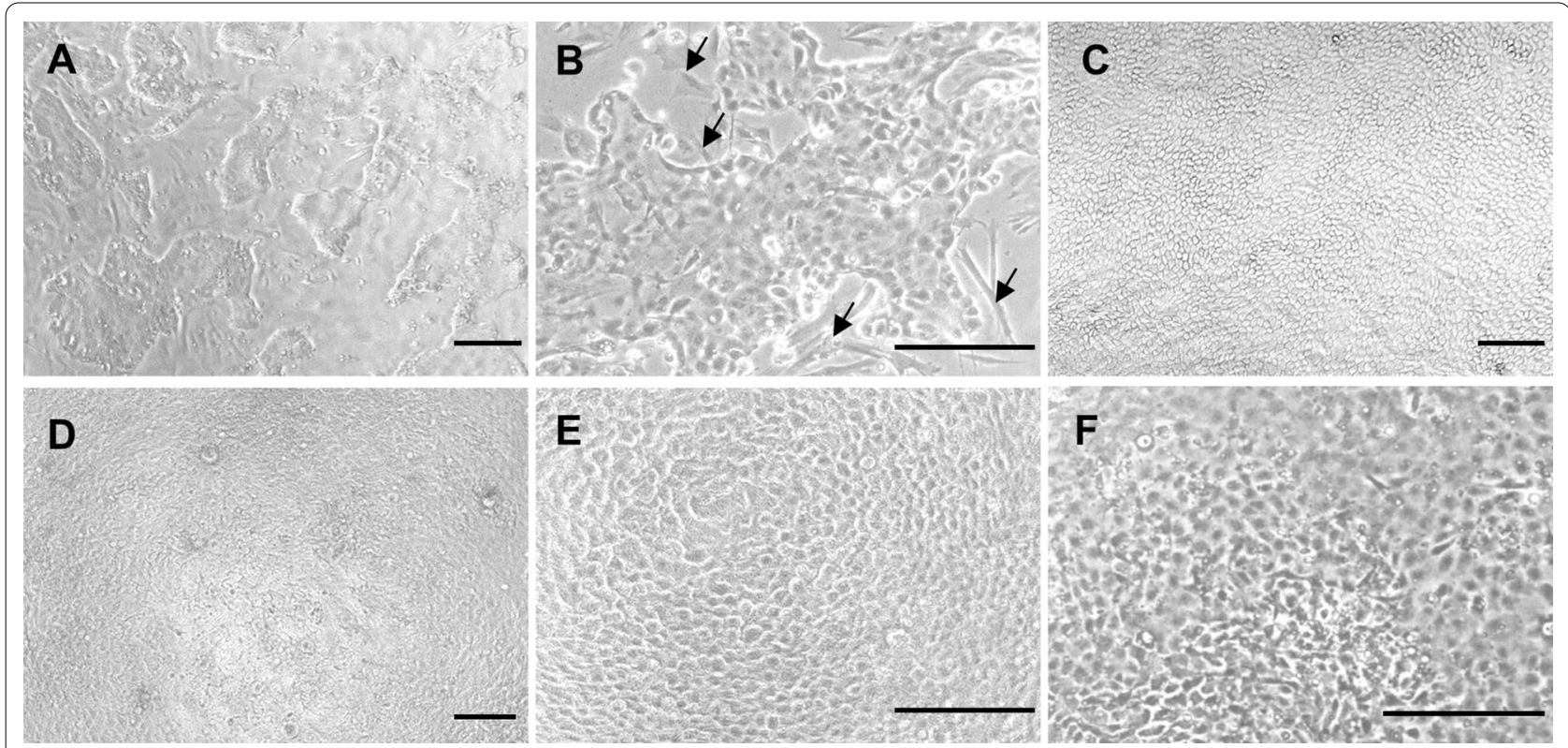

Figure 1 Growth and formation of 2D enteroids. 2D enteroid grown on Matrigel-coated cell culture plastic. A Bright field image of epithelial cells forming islands on day 1 of culture. B Fibroblast-like cells seen around the edge of the epithelial cell islands (arrows). C A confluent polygonal epithelial cell layer on day 3 and on $\mathbf{D}$ day 6 of cell culture. $\mathbf{E}$ Higher magnification of 2D enteroid on day 6 of culture. $\mathbf{F}$ Bright field image of 2D enteroid grown on an uncoated cell culture plastic. Representative images of 5-6 independent experiments. Scale bars: $100 \mu \mathrm{m}$.

identified intra-epithelial leukocytes in the 2D enteroids (Figures 2A-F). The presence of stem cells was confirmed by Lgr5 mRNA expression (Figure 2G).

Further characterisation indicated that the cultures consisted of two cell layers with a sub-epithelial cell layer of mesenchymal cells. These cells expressed $\alpha$-smooth muscle actin and desmin mRNA (Figures $3 \mathrm{~A}$ and B). The sub-epithelial layer was revealed by staining of vimentin after removal of the apical cells, (Figures $3 \mathrm{C}$ and D) and by co-staining of vimentin and E-cadherin (Figures $3 \mathrm{E}$ and F). A Z-stack of immunolocalisation of F-actin and nuclei (DAPI) in the 2D enteroids showed basal nuclei and long F-actin filaments characteristic of mesenchymal cells in the basal slices (Figures 3G-J). The data also confirms the epithelial layer is polarised, with the apical side facing the media, while the basolateral region contained a layer of mesenchymal cells. These results show that we have generated an ex vivo $2 \mathrm{D}$ enteroid intestinal culture that recapitulates all differentiated epithelial cells and a sub-epithelial mesenchymal cell layer with similarity to the chicken intestine.

\section{Intestinal epithelial cells form a tight cell layer on transwells}

We next tested the ability of the $2 \mathrm{D}$ enteroids to form a function barrier, an essential parameter for a physiological relevant intestinal model. Expression of the tight junction protein Zona Occludens 1 (ZO1) was detected in the epithelial cells connecting the cytoskeleton of adjacent cells (Figure 4A). We measured paracellular permeability of the 2D enteroids to small molecules by diffusion of $4 \mathrm{kDa}$ FITC-dextran in a transwell system. Measurement of fluorescence in the basal compartment demonstrated minimal transport was observed from day 3 of culture (Figure 4B), whereas in control wells with no cells, significantly more movement of FITC-dextran into the basal compartment was detected. Using the transwell system, we measured TEER and found that from day 3 of culture the $2 \mathrm{D}$ enteroids reproducibly gave a consistent TEER value of $4000-4500 \Omega \cdot \mathrm{cm}^{2}$ (Figure $4 C$ ) which lasted to day 7 . The drop in TEER at day 8 was not caused by cell death, but due to the apical and basal layer detaching from the edge of the transwell or less frequently by the appearance of holes in the apical layer. At day 2 of culture when the 2D enteroid was not completely developed, some level of paracellular permeability was observed which was consistent with the sub-optimal TEER measurement at this timepoint.

\section{Manipulation of epithelial integrity of the 2D enteroids}

To investigate the functional capability of the $2 \mathrm{D}$ enteroids we first tested several factors known to modulate and maintain epithelial integrity. First, we altered the duration of Wnt activator CHIR99021 in the Seeding Media for $24 \mathrm{~h}$ (control) and then to the Maintenance Media at $48 \mathrm{~h}$ or $72 \mathrm{~h}$, and the prolonged presence significantly 

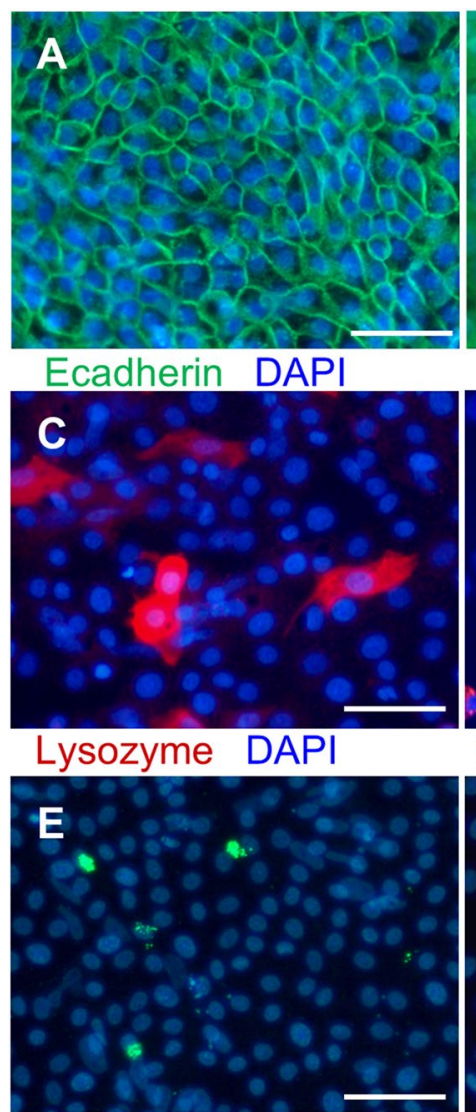

Muc5AC DAPI

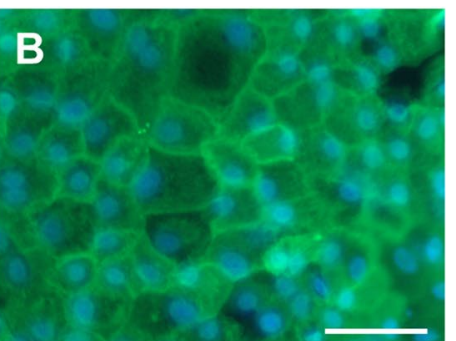

Villin DAPI
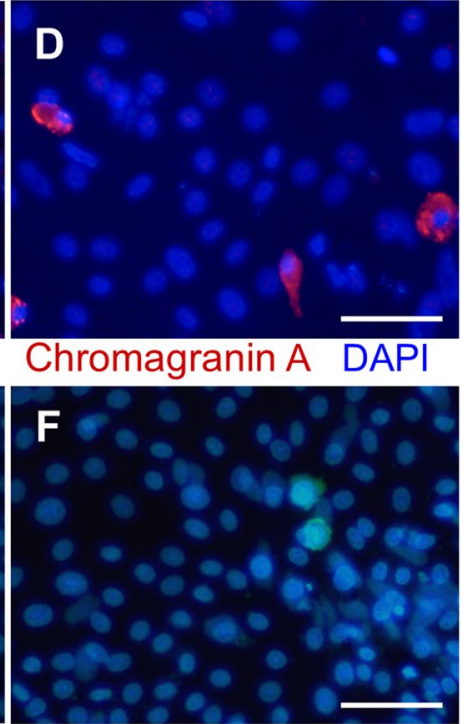

CD45 DAPI

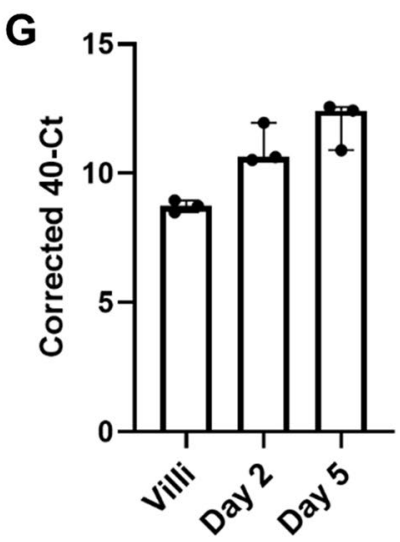

Figure 2 Cellular characterisation of the apical layer of 2D enteroids. Immunolocalisation of (A-F) apical epithelial cell types in 2D enteroids grown on Matrigel coated cell culture plastic at day 6 of culture. All cells are counterstained with DAPI (blue). The cells are stained for $\mathbf{A}$ E-cadherin (epithelial cells with adherens junctions, green) and vimentin (red), but vimentin expression is not evident in the sub-epithelial layer after mild cell permeabilisation with saponin, B villin (enterocytes, green), C Lysozyme (Paneth cells, red), D Chromogranin A (enteroendocrine cells, red), E Muc5AC (Goblet cells, green), and F CD45+ (leukocytes, green). Representative images from 3-4 independent experiments. Scale bars: 50 um. G mRNA expression of the stem cell marker Lgr 5 in freshly isolated villi, at day 2 and 5 of culture, grown on uncoated cell culture plastic. Data represents the median and $95 \% \mathrm{Cl}$ of three independent experiments.

increased the duration of the maximum TEER from day 7 up to day 9 of culture (Figure 5A).

Second, we investigated the effect of increasing the $\mathrm{Ca}^{2+}$ concentration on $2 \mathrm{D}$ enteroid integrity. The Basal Media Advanced/DMEM F12 (control) has a relatively low concentration of $\mathrm{Ca}^{2+}(1.05 \mathrm{mM})$ in comparison to the $1.8 \mathrm{mM} \mathrm{Ca}^{2+}$ physiological concentration of many cell culture media. The effect of increased $\mathrm{Ca}^{2+}$ concentrations in the Maintenance Media resulted in prolonged maximum TEER levels in a concentration-dependent manner (Figure 5B).

Third, we investigated the effect of sodium butyrate $(\mathrm{NaB})$ on $2 \mathrm{D}$ enteroid epithelial integrity. $\mathrm{NaB}$ is known to regulate tight junction assembly of the gut epithelial layer. $\mathrm{NaB}$ prolonged the duration of the maximum TEER in a concentration-dependent manner; addition of $7 \mathrm{mM}$
$\mathrm{NaB}$ extended the maximum TEER beyond control, day 7, up to day 9 of culture (Figure 5C). Thus, the 2D enteroids demonstrated the functional ability to respond to Wnt activation, increased $\mathrm{Ca}^{2+}$ concentration and $\mathrm{NaB}$, to support and protect epithelial junction integrity during prolonged cell culture.

Following the observed positive effect of $\mathrm{NaB}$ on our $2 \mathrm{D}$ enteroid model of a healthy gut, we investigated the ability of $\mathrm{NaB}$ to rescue or restore epithelial integrity to a leaky gut with reduced epithelial integrity. A leaky gut model was generated by manipulation of the 2D enteroids; switching to LCM media $\left(0.26 \mathrm{mM} \mathrm{Ca}^{2+}\right.$ concentration) from day 3 of culture, when confluency and maximum TEER was established resulted in a drop in TEER. Restoration of the $\mathrm{Ca}^{2+}$ concentration to control levels $(1.05 \mathrm{mM})$ by addition of $\mathrm{CaCl}_{2}$ restored the 

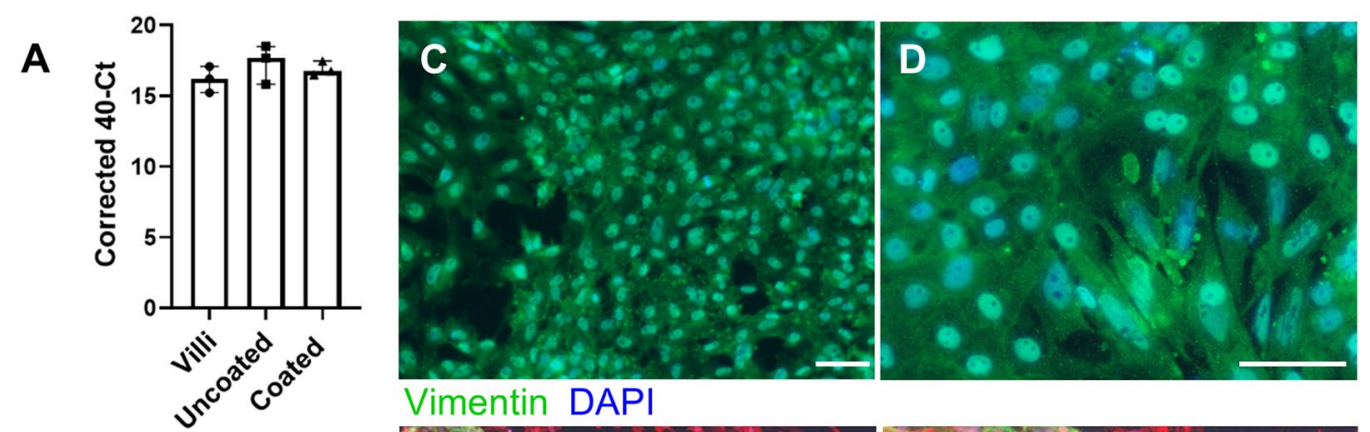

B
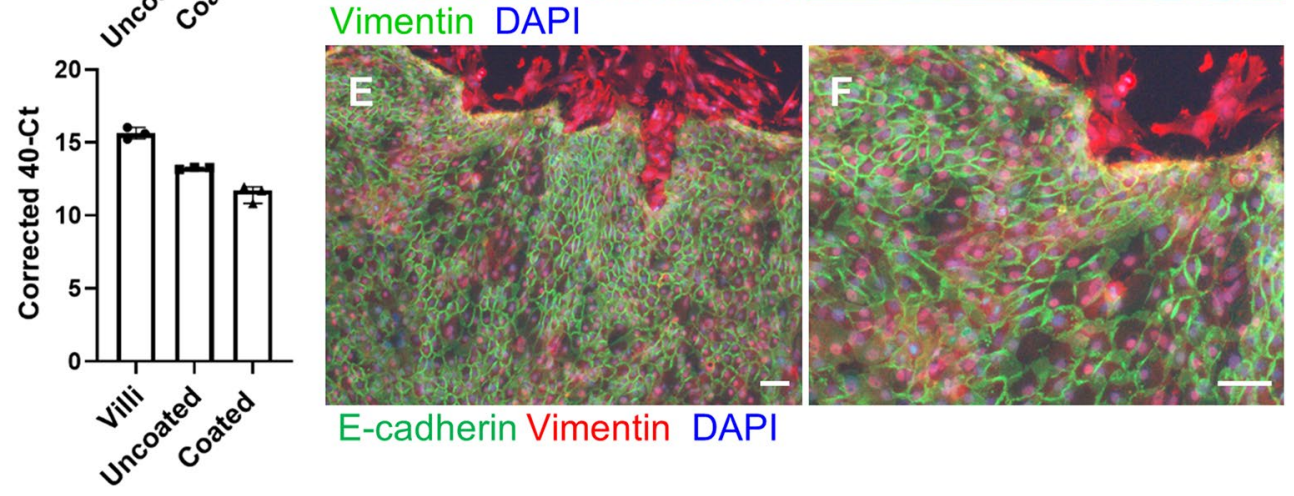

\section{E-cadherin Vimentin DAPI}
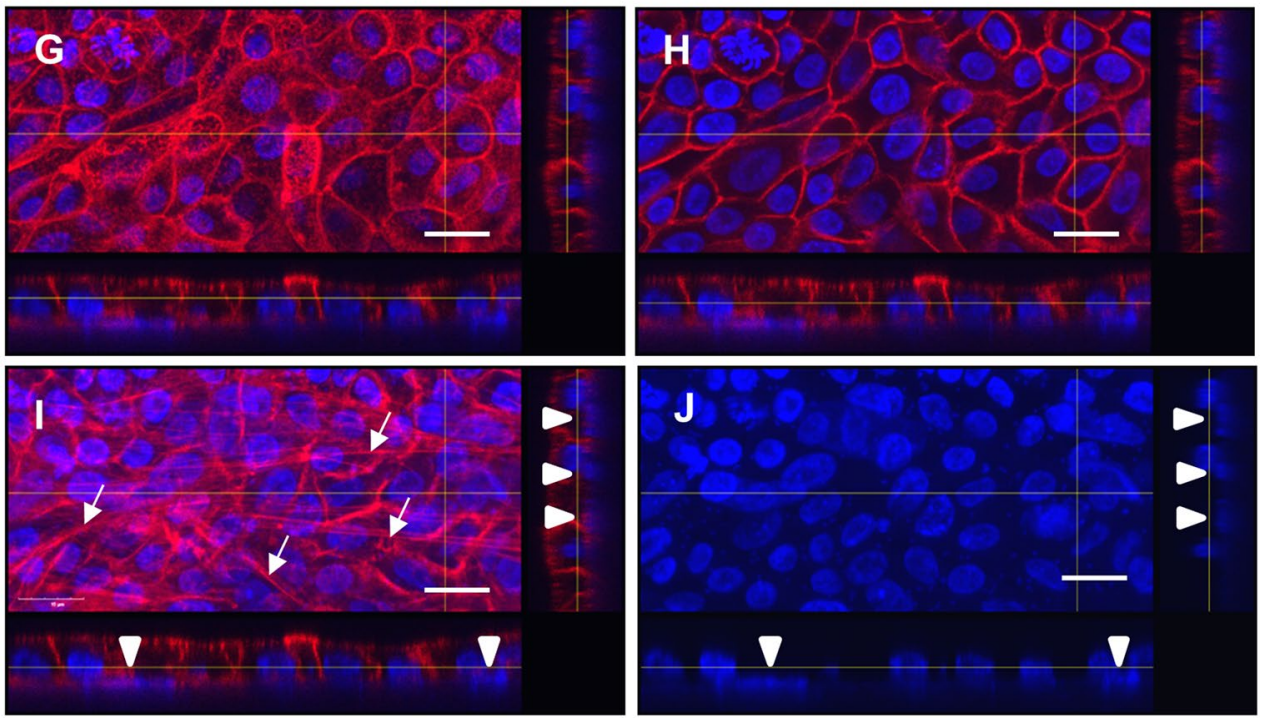

\section{F-actin DAPI}

Figure 3 Cellular characterisation of the basal layer of $2 \mathbf{D}$ enteroids. mRNA expression of $\mathbf{A}$ a-smooth muscle actin and $\mathbf{B}$ desmin in freshly isolated villi and in 2D enteroids grown on uncoated and Matrigel coated cell culture plastic at day 5 of culture. Data is represented as the mean of three independent experiments and $95 \% \mathrm{Cl}$. Immunolocalisation of basal mesenchymal cell types in 2D enteroids grown on Matrigel coated cell culture plastic $(\mathbf{C}-\mathbf{F})$ or transwells $(\mathbf{G}-\mathbf{I})$. After removal of the apical cells, the cells are stained for $\mathbf{C}, \mathbf{D}$ vimentin (mesenchyme, green). E, F To demonstrate the subepithelial layer, the cells are permeabilised with Triton X100 on day 2 and double stained for E-cadherin (epithelial cells with adherens junctions, green) and vimentin (mesenchyme, red). Vimentin expression is evident in the sub-epithelial layer. Images from 3 independent experiments. All cells are counterstained with DAPI (nuclei, blue). Scale bars: $50 \mu \mathrm{m}$. (G-J) Immunolocalisation of F-actin (red) and DAPI (nuclei, blue) in 2D enteroids grown on Matrigel coated transwells at day 4 of culture. Z- stack of $\mathbf{G}$ Apical, $\mathbf{H}$ Middle and I, J Basal slices. I, J DAPI stained nuclei in the basal slices demonstrate the presence of nuclei in the subepithelial layer (white arrowheads), whereas long F-actin filaments from mesenchymal cells (I) cross the basal layer slice (white arrows). The lines on the main photo indicate the image area represented in the transverse slices at the bottom and side of each photo. Representative images of 1 experiment. Scale bars: $15 \mu \mathrm{m}$. 


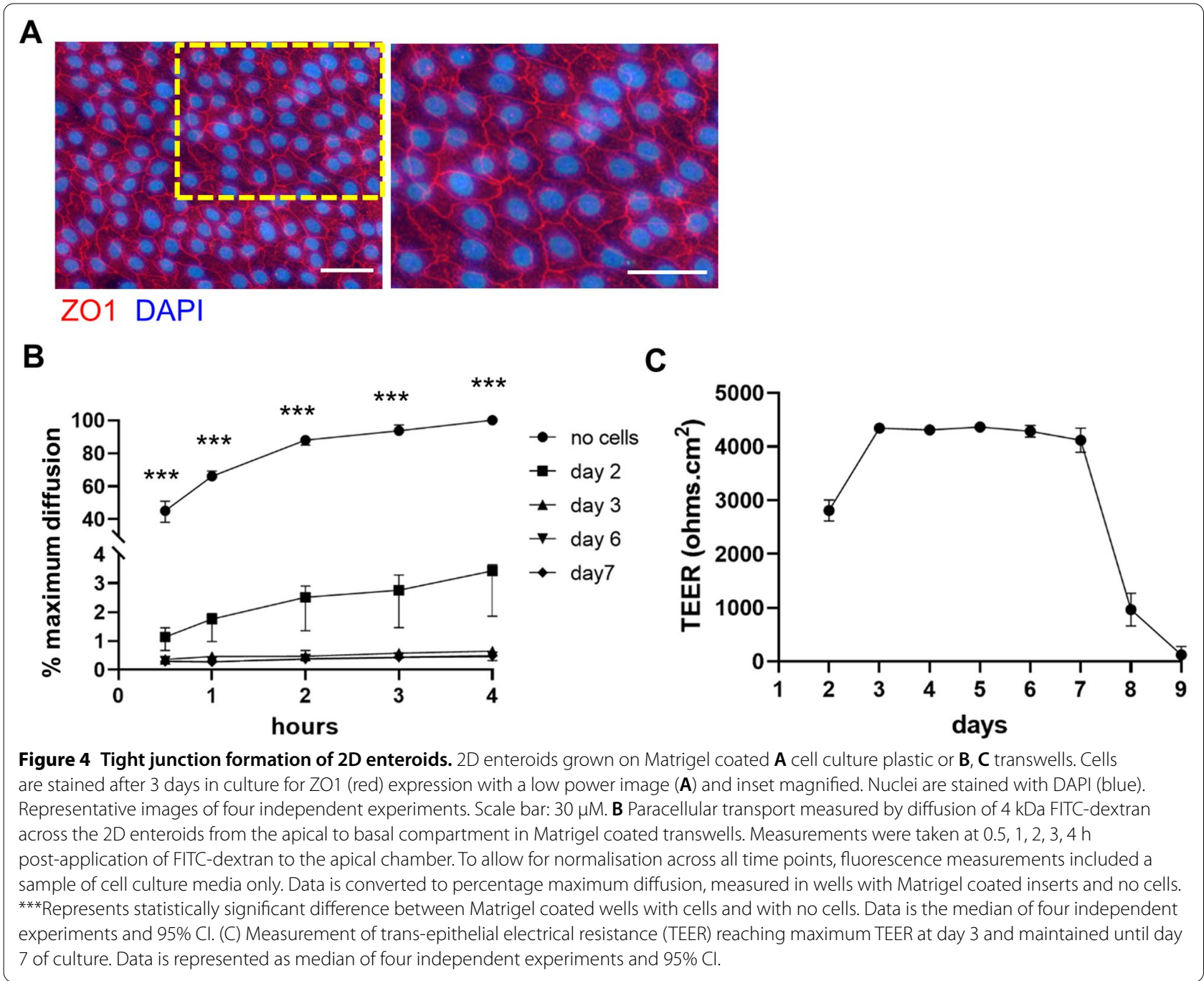

maximum TEER values (Figure 5D). Similarly, $\mathrm{NaB}$ added to $2 \mathrm{D}$ enteroids cultured in LCM media was also able to restore epithelial integrity. In LCM media, the maximum TEER measured in the 2D enteroids declined from day 5 of culture, but in the presence of $\mathrm{NaB}$ the maximum TEER was maintained until day 8 (Figure 5D).

\section{Stimulation of 2D enteroids with bacterial endotoxins}

Next, the 2D enteroids were exposed to bacterial endotoxins and epithelial integrity and innate immune responses were assessed. LPS from $S$. Typhimurium, $S$. Enteritidis and E. coli or heat-killed bacteria (Figures 6AD) were added to Maintenance Media in the apical and basal compartments of the 2D enteroids grown on transwells. HiAPEC and LPS up to $10 \mu \mathrm{g} / \mathrm{mL}$ had no effect on the epithelial barrier based on TEER values. Next, day 5 cultures were treated with LPS from $S$. typhimurium or LTA from B. subtilis and IL- 6 and IL-8 mRNA expression determined $6 \mathrm{~h}$ after treatment. IL- 6 and IL-8 mRNA expression significantly increased in a dose-dependent manner, while LTA had a minimal effect (Figure 7). The 2D enteroids demonstrated the ability to produce appropriate innate immune responses when exposed to pathogenic and pro-biotic bacterial products.

\section{Cryopreservation of 2D enteroids}

Since passaging of the 2D enteroids is not yet feasible, a protocol that will allow cryopreservation of single cells was developed. The frozen isolated cells could be successfully thawed and formed polarised 2D enteroids 3 days post-seeding containing all epithelial cell lineages (Figures $8 \mathrm{~A}-\mathrm{E}$ ) and with a sub-epithelial mesenchymal cell layer present (Figures $8 \mathrm{~F}$ and G). Thawed cells cultured with CHIR99021 for the first $24 \mathrm{~h}$ had similar TEER readings as freshly isolated cells but TEER levels decreased from day 6 (Figure $8 \mathrm{H}$ ). When thawed cells were cultured 

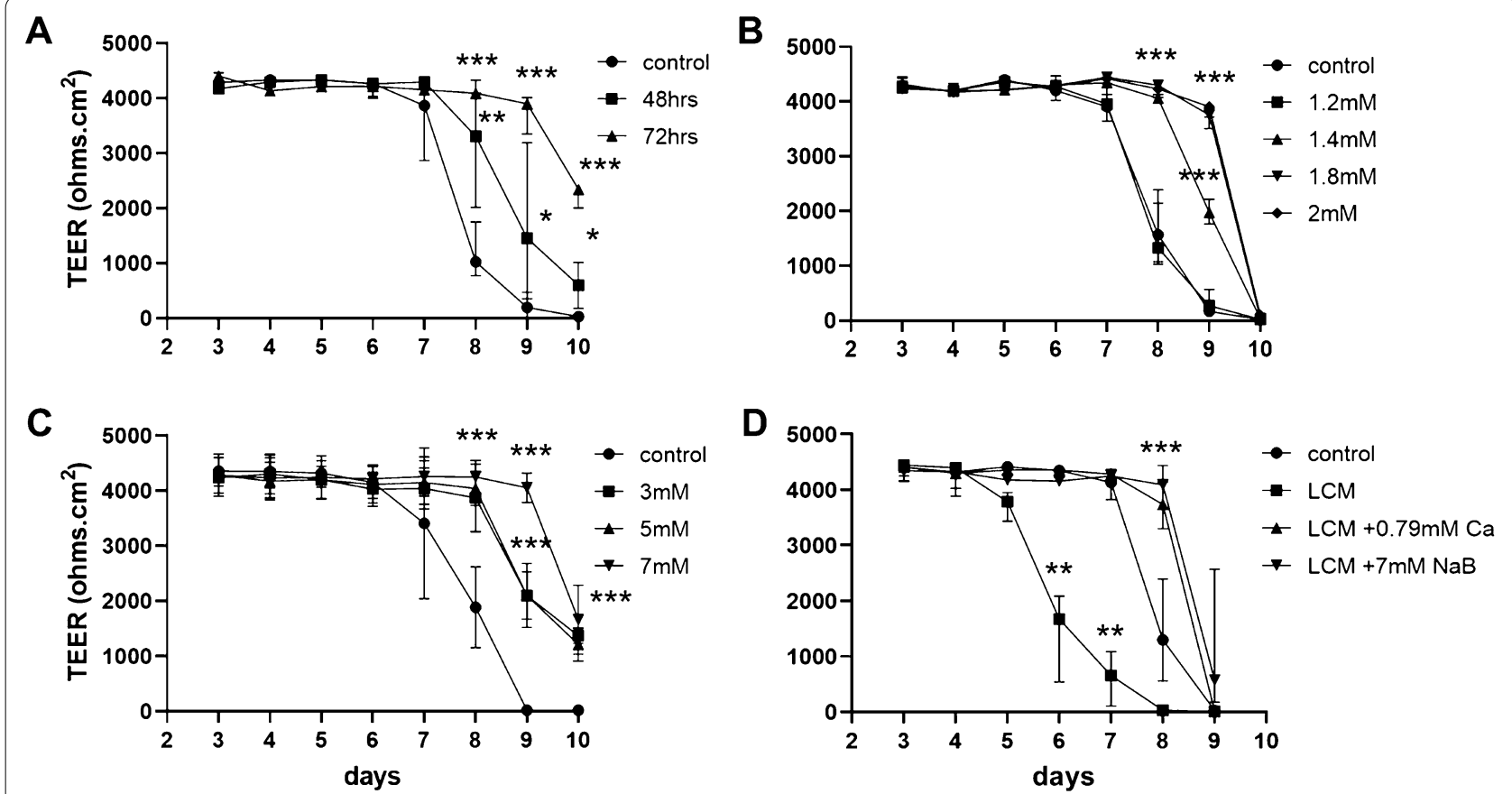

Figure 5 Enhancement of intestinal epithelial integrity. 2D enteroids grown on Matrigel coated transwells. The duration of the maximum TEER of 2D enteroids grown can be extended by $\mathbf{A}$ addition of CHIR99021 (10 mM) in the culture media from initial seeding for longer than $24 \mathrm{~h}$ (control, 24 h), B increasing Ca ${ }^{2+}$ concentration from control concentration $1.05 \mathrm{mM}$ to $2 \mathrm{mM}$ by addition of calcium chloride (duplicate wells) or by $\mathbf{C}$ addition of sodium butyrate ( $\mathrm{NaB} ; 3,5,7 \mathrm{mM}$; duplicate wells). $\mathbf{D} \mathrm{NaB}$ and $\mathrm{Ca}^{2+}$ rescue epithelial integrity of a leaky gut model of $2 \mathrm{D}$ enteroids grown in low calcium media ( $\mathrm{LCM}$ with $0.26 \mathrm{mM} \mathrm{Ca}^{2+}$ ). The barrier integrity could be rescued by restoring Ca ${ }^{2+}$ concentration to the control concentration (1.05 $\mathrm{mM} \mathrm{Ca}^{2+}$ ) or by adding $\mathrm{NaB}(7 \mathrm{mM})$ from day 3 of culture. All additions were made every second day, from day 3 of culture, to the apical and basal compartments of the transwell. Statistical significance compared to control wells are ${ }^{*} P<0.05,{ }^{* *} 0.05<P>0.001,{ }^{* *} P<0.001$. Data is presented as the median of 3-5 independent experiments and 95\% Cl.

with CHIR99021 for $72 \mathrm{~h}$, an increase in barrier integrity based on maximum TEER measurements was found from day 6 up to day 11 (Figure 8I). Increasing the cell seeding density to $2 \times 10^{5}$ cells/well in the latter experiment enabled to extend the maximum TEER similar to fresh cells grown under the same conditions.

\section{Discussion}

Generating well-characterised ex vivo models of the chicken intestine is an essential advancement in poultry research to study their physiology and disease states, to improve health and minimise the number of animal studies. Recent advances in the generation of 3D chicken enteroids have improved the complexity of the cultured organoids to closer resemble native tissue [25], but 2D chicken intestinal models are still relatively primitive with partial characterisation of epithelial cell types, lacking the multi-cellular interactions found in vivo, and with limited scope for functional studies [17-24, 27]. Here, we describe the generation of a confluent 2D epithelial layer from ED18 embryos with all epithelial cell lineages and a sub-epithelial mesenchymal layer, which mirror the architecture of the intestinal lining in vivo. The $2 \mathrm{D}$ enteroids were grown successfully in transwell format, with robust epithelial integrity up to 11 days and demonstrating innate immune responses. The derivation of $2 \mathrm{D}$ and 3D intestinal enteroids in mammalian species is commonly from the crypts containing stem cells, in contrast the villi of ED18 embryonic chickens were used for the generation of $2 \mathrm{D}$ and $3 \mathrm{D}$ enteroids, because crypts are at a rudimentary stage of development. It takes to $48 \mathrm{~h}$ post hatch for intestinal invaginations to complete with crypt enlargement and fission continuing over 9 days post-hatch [29]. The protocols for preparation of chicken intestinal epithelial cultures are commonly from late-stage embryonic chicks, and therefore by definition derived from villi [17-24, 27]. A mixed population of disaggregated villi cells when randomly seeded was able to generate a self-organised apical layer containing enterocytes, Goblet cells, Paneth cells, enteroendocrine cells and leukocytes and a sub-epithelial mesenchymal layer.

The intestinal mesenchyme is involved in regulation of the intestinal epithelium [2] and can also act as non-professional immune cells [34] during homeostasis, 


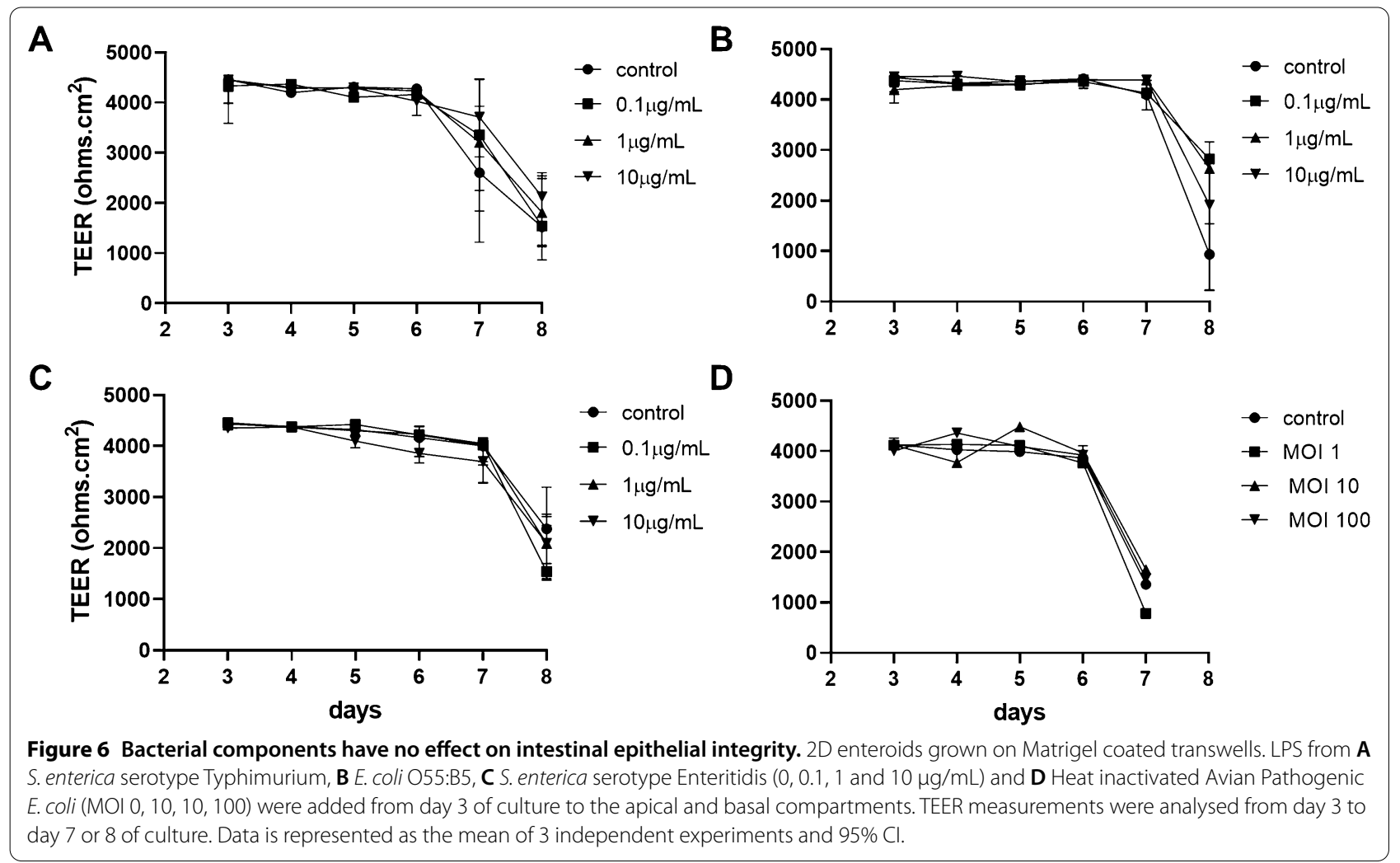

A

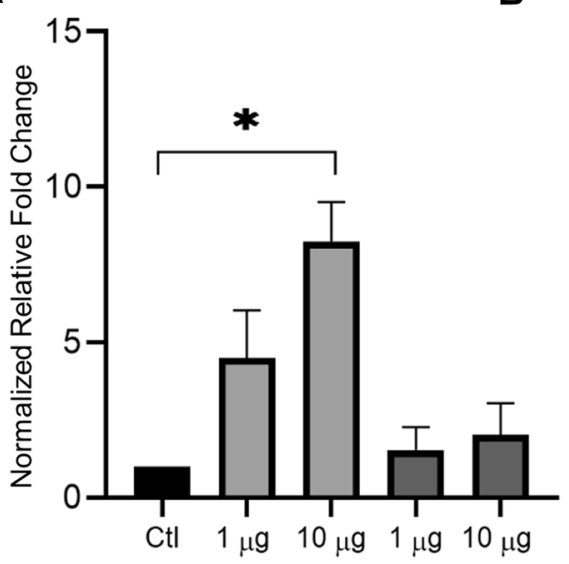

B
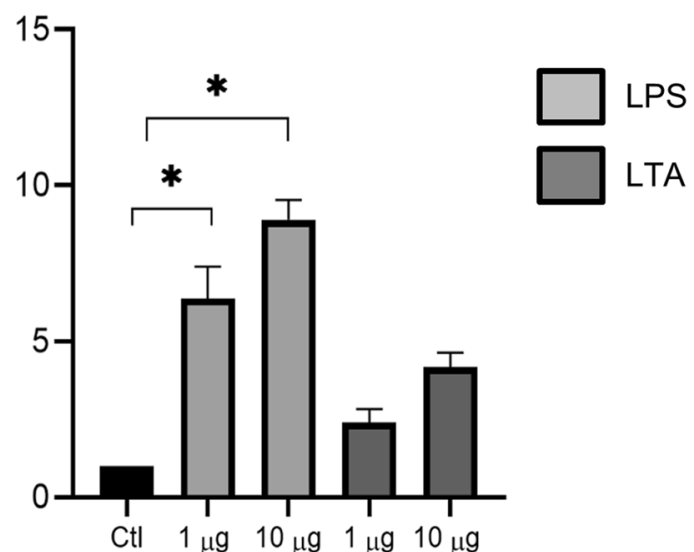

Figure 7 Bacterial components induce inflammatory responses in 2D enteroids. Confluent 2D enteroids cultured on uncoated plastic wells were treated on day 5 for $6 \mathrm{~h}$ with LTA from Bacillus subtilis or LPS from S. enterica serotype Typhimurium ( 1 and $10 \mu \mathrm{g} / \mathrm{mL}$ ). Inflammatory responses are assessed by qRT-PCR $\mathbf{A} \| \mathrm{L}-6$ and $\mathbf{B} \| \mathrm{L}-8$ (CXCLi2) mRNA expression shown as fold change relative to control 2D enteroids. Statistical significance calculated in comparison to control cells and shown as $* P<0.05$. Data is the median of four independent experiments and $95 \% \mathrm{Cl}$.

inflammation, injury and repair. The process of spontaneous self-organisation into segregated cell layers from pools of multiple cell types has been demonstrated in other culture systems, for example, formation of models of the skin [35]. The major subsets of mesenchymal cells in the villi are fibroblasts, myofibroblasts and pericytes, and each subset can express one or more markers, vimentin, desmin and $\alpha$-smooth muscle actin $[2,34,36]$, which were all identified in the $2 \mathrm{D}$ enteroids. The overlapping nature of marker gene expression in intestinal 

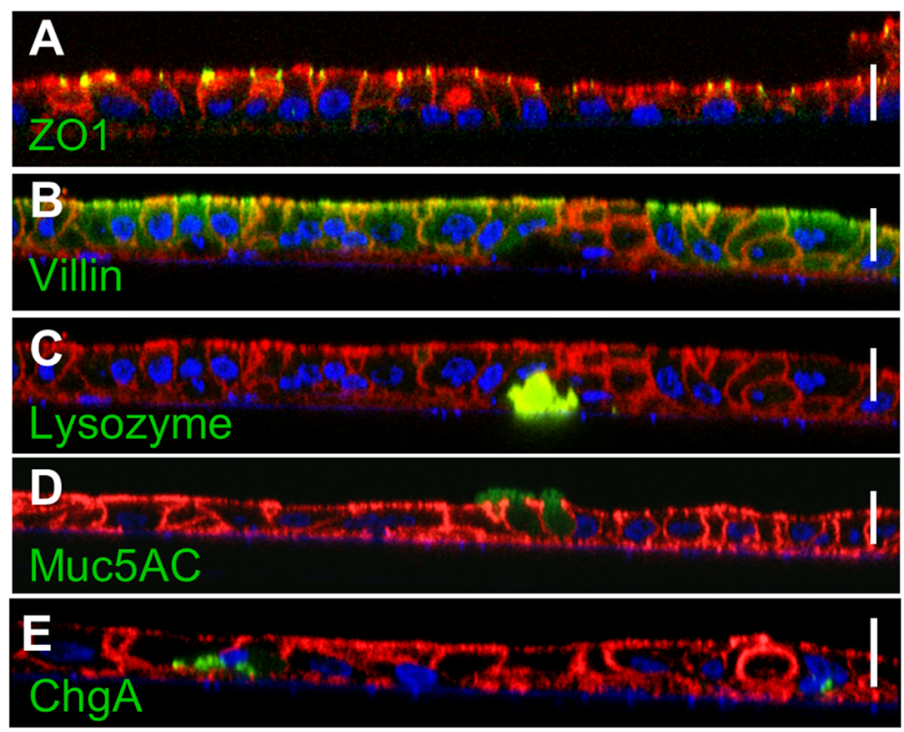

F-actin DAPI

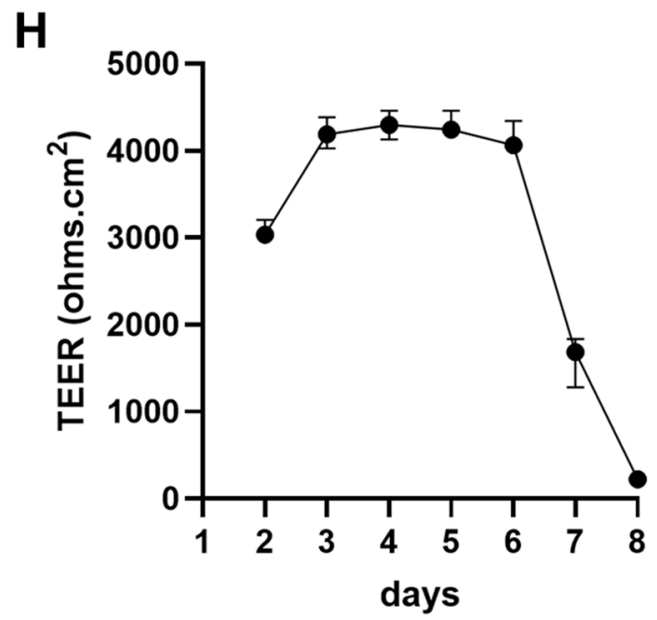

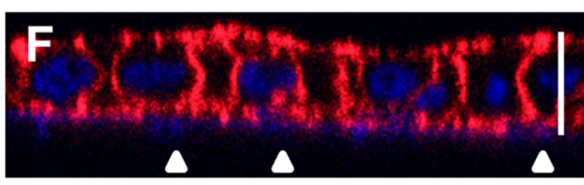
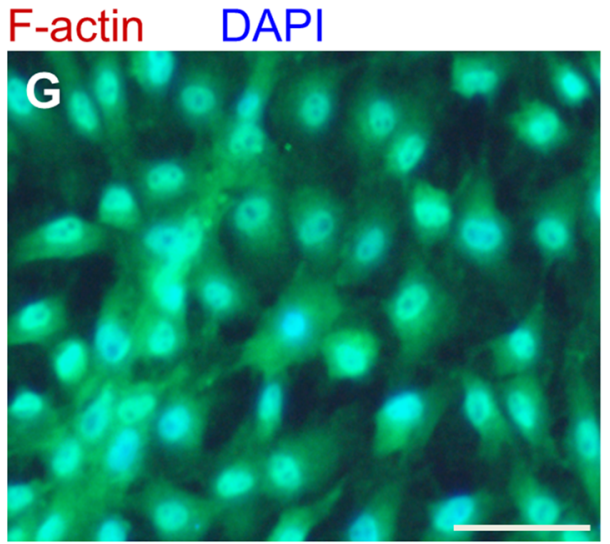

Vimentin DAPI

Figure 8 Resurrection and cellular characterisation of 2D enteroids after cryopreservation. Immunolocalisation of 2D enteroids grown from cryopreserved intestine cells on Matrigel-coated transwells, on day 4 of culture. Z stack of co-immunolocalisation of F-actin (apical brush border, red) with intestinal epithelial cells (green); A ZO1 (Tight Junctions), B Villin (enterocytes), C Lysozyme (Paneth cells), D Muc5AC (Goblet cells) and E Chromogranin A (enteroendocrine cells). F Magnification of Z-stack of Muc5AC showing DAPI stained nuclei in basal cells (white arrow heads). Scale bars: $15 \mu \mathrm{m}$. G Vimentin expression (green) in basal mesenchymal cells in the absence of epithelial cells. Scale bar: $50 \mu m$. Nuclei are stained with DAPI. The data represents three independent experiments. H, I Cells were thawed and grown as 2D enteroids in transwells; CHIR99021 was added to Maintenance Media for $\mathbf{H} 24 \mathrm{~h}$ and $\mathbf{I} 72 \mathrm{~h}$. Data is the median of 3-4 independent experiments and $95 \% \mathrm{Cl}$.

mesenchymal cells means in the absence of co-localisation studies, cell types in this study are not specified. Mesenchymal cells are often included in intestinal epithelial cultures to support their long-term maintenance [11] and also to generate more organotypic cultures [37]. Long-term cultures were not achieved in our study, but the maximum culture duration of the $2 \mathrm{D}$ enteroids (11 days) is not prohibitive to most experiments investigating intestinal permeability and integrity.
The growth factor requirements for maintaining mammalian 3D organoids and intestinal monolayer cultures have been well defined, and consist of Epidermal Growth Factor, Noggin, and R-Spondin (ENR) [4, 9, 12, 20]. The culture conditions of the chicken 2D enteroids were established using a modified ENR growth factor cocktail previously used in mouse intestinal monolayer cultures [12]. In the early culture period additional factors were added including GSK3 $\beta$ inhibitor, which acts as a Wnt 
activator to support stem cells, proliferative cells and Paneth cells [12, 22, 38] and Rock inhibitor to prevent anoiksis that occurs in dissociated intestine cells ex vivo $[39,40]$.

The generation of $2 \mathrm{D}$ intestinal cultures with a tight epithelium has not previously been reported in chicken [17-24, 27]. Most recently, confluent cultures of primary chicken duodenal epithelial cells were described [20]. These cultures survive until day 12 with tight junctions and a low TEER value of $64 \Omega \cdot \mathrm{cm}^{2}$, which is in line with some other intestinal cell models but does not indicate a tight barrier [41]. For comparison, in chicken, TEER values of greater than $10000 \Omega \cdot \mathrm{cm}^{2}$ have been measured in duodenum explants [42]. In the $2 \mathrm{D}$ enteroids, lack of paracellular flux of $4 \mathrm{kDa}$ FITC-dextran, robust TEER values $\left(\sim 4000 \Omega \cdot \mathrm{cm}^{2}\right)$ and immunolocalisation of $\mathrm{ZO} 1$, to the apical surface of the epithelium demonstrated the development of a tight functional epithelial barrier.

As a proof-of-concept, the epithelial barrier of the 2D enteroids was positively and negatively manipulated by CHIR99021, $\mathrm{Ca}^{2+}$ and NaB. CHIR99021 was added to the early 2D enteroid cultures to support cell growth and might be expected to play a similar role when added to the cultures for longer $[12,22,38]$. An optimal $\mathrm{Ca}^{2+}$ concentration is important for tight junction assembly and stabilisation and depletion of $\mathrm{Ca}^{2+}$ in cultures of differentiated intestinal cells causes a decrease in epithelial integrity $[43,44]$ as demonstrated in our leaky gut model. The role of $\mathrm{Ca}^{2+}$ concentration in the $2 \mathrm{D}$ enteroids and leaky gut model is likely to be through support of intercellular junctions or forming de novo junctions, to maintain and restore epithelial integrity as in other intestinal cell models [43, 44]. Butyrate is used as a feed supplement and alternative to antibiotics and has several roles in the chicken intestine, including support of immune function $[45,46]$ and possible regulation of tight junction assembly as has been found in intestinal cell lines [47, 48]. The protective and supportive effect of $\mathrm{NaB}$ on epithelial integrity found in the $2 \mathrm{D}$ enteroids and leaky gut model is consistent with previous reports of $\mathrm{NaB}$ able to increase intracellular calcium, activation of the AMPKactivated protein kinase pathway and synthesis of tight junctions in intestine cells [44, 47, 48]. Thus, the chicken $2 \mathrm{D}$ enteroids represent a functional model for investigating factors, which regulate epithelial integrity.

Pathogen infection in the intestine can cause epithelial apoptosis, release of inflammatory cytokines, inflammation and decrease in tight junction proteins [1]. Bacterial endotoxins can disrupt intestinal barrier function in vivo in mouse [49] and chickens $[50,51]$. When the 2D enteroids were cultured in the presence of LPS or killed APEC, no effect on epithelial integrity was found. LPS alone has been shown previously to not always be sufficient to cause a significant effect on epithelial integrity $[52,53]$ and the necessity to co-culture with peripheral blood mononuclear cells for LPS to disrupt the epithelium has been reported [54, 55]. To protect epithelial integrity, the intestinal epithelium maintains some hypo-reactivity to microbial ligands as it is constantly exposed to the microbiome. Further, the usual invasive activity of enteropathogenic E. coli and Salmonella through the type III secretion system [56, 57] may be important to target the actin cytoskeleton and alter membrane integrity. In future studies, the use of invasive bacteria or a co-culture model to investigate the effects of pathogens on epithelial integrity will be tested.

Innate immune responses are critical in the first week post-hatch $[45,58]$. Upregulation of inflammatory cytokines, IL-6 and IL-8 mRNA expression found in the 2D enteroids exposed to LPS from S. Typhimurium is also previously reported in in young chickens $[59,60]$ and intestinal epithelial cells $[18,61]$. IL-6 and IL-8 may alter epithelial integrity however, it was suggested that their expression alone may not be sufficient to induce significant changes in intestinal epithelial monolayers [55]. Conversely, multiple strains of probiotic $B$. subtilis are used as a safe alternative to antibiotics in chickens, and to promote growth, immunity, epithelial integrity and overall gut health $[62,63]$ and which is consistent with a minimal effect of LTA from $B$. subtilis in the $2 \mathrm{D}$ enteroids. Extensive investigation of the innate immune response in the $2 \mathrm{D}$ enteroids in response to microorganisms is a topic for future studies.

Overall, we have developed a protocol to generate chicken $2 \mathrm{D}$ enteroids which can be used to perform standardised high-throughput studies of intestinal epithelial cell biology and innate immune function, investigating ways to improve and support intestinal health, and which can be extended to other broader applications.

\section{Abbreviations \\ 2D: 2 Dimensional; 3D: 3 Dimensional; APEC: Avian Pathogenic Escherichia coli; DMEM: Dulbecco's modified eagle medium; ED: Embryonic day; EGF: Epidermal growth factor; GADPH: Glyceraldehyde phosphate dehydrogenase; HiAPEC: Heat inactivated Avian Pathogenic Escherichia coli; IL-6: Interleukin 6; IL-8/CXCLi2: Interleukin 8; LCM: Low calcium media; LPS: Lipolysaccharide; LTA: Lipoteichoic acid; MOI: Multiplicity of infection; NaB: Sodium butyrate; PBS: \\ Phosphate buffered saline; r28S: Ribosomal 28S; TEER: Trans epithelial electrical resistance; ZO1: Zona occludens 1.}

\section{Acknowledgements}

The authors would like to thank the staff in the National Avian Research facility for help with tissue collection. We express our gratitude to Prof. Lisa Nolan for originally providing the APEC $\mathrm{O} 1$ strain and Dr. K. Bryson for growing up the E. coli. We are grateful to DrT. Hansen (Novozymes) for fruitful discussions and support.

\section{Authors' contributions}

$\mathrm{BO}, \mathrm{SJ}$ and LV conceptualised the study; LV, SJ, and MG secured funding to undertake the work and supervised the project; $\mathrm{BO}, \mathrm{KS}$ and SC performed the experiments and analysed the data with technical support of TN, HN and LH. 
BO wrote the manuscript supported by KS, SC, SJ, and LV. All authors read and approved the final manuscript.

\section{Funding}

This research was supported by Novozymes A/S and Institute Strategic Program Grant and funding from the Biotechnology and Biological Sciences Research Council (BBS/E/D/10002071 and BBS/E/D/20002174).

\section{Declarations}

\section{Ethics approval and consent to participate}

Experiments were performed using embryonic day (ED18) Hy-Line Brown chickens (Gallus gallus) obtained from the National Avian Research Facility, Edinburgh, UK or Lohmann-LSL-LITE Layers from Lohmann, Denmark. Ethical approval was obtained from the Roslin Institute's and University of Edinburgh Animal Welfare Ethics Review Board. The experiments were performed under the authority of UK Home Office Licenses (PE263A4FA) in accordance within the guidelines and regulations of the UK Home Office "Animals scientific procedures Act 1986".

\section{Competing interests}

The authors declare that they have no competing interests.

\section{Author details}

'Division of Infection and Immunity, The Roslin Institute and Royal (Dick) School of Veterinary Studies, University of Edinburgh, Edinburgh, Midlothian, UK. ${ }^{2}$ Novozymes A/S, Animal Health and Nutrition, 2800 Lyngby, Denmark.

Received: 16 June 2021 Accepted: 22 October 2021

Published online: 24 November 2021

\section{References}

1. Peterson LW, Artis D (2014) Intestinal epithelial cells: regulators of barrier function and immune homeostasis. Nat Rev Immunol 14:141-153

2. Roulis M, Flavell RA (2016) Fibroblasts and myofibroblasts of the intestinal lamina propria in physiology and disease. Differentiation 92:116-131

3. Fujii M, Matano M, Toshimitsu K, Takano A, Mikami Y, Nishikori S, Sugimoto S, Sato T (2018) Human intestinal organoids maintain self-renewal capacity and cellular diversity in niche-inspired culture condition. Cell Stem Cell 23:787-793.e786

4. Sato T, Stange DE, Ferrante M, Vries RGJ, van Es JH, van den Brink S, van Houdt WJ, Pronk A, van Gorp J, Siersema PD, Clevers H (2011) Long-term expansion of epithelial organoids from human colon, adenoma, adenocarcinoma, and Barrett's epithelium. Gastroenterology 141:1762-1772

5. Sato T, Vries RG, Snippert HJ, van de Wetering M, Barker N, Stange DE, van Es JH, Abo A, Kujala P, Peters PJ, Clevers H (2009) Single Lgr5 stem cells build crypt-villus structures in vitro without a mesenchymal niche. Nature 459:262-265

6. Khalil HA, Lei NY, Brinkley G, Scott A, Wang J, Kar UK, Jabaji ZB, Lewis M, Martín MG, Dunn JC, Stelzner MG (2016) A novel culture system for adult porcine intestinal crypts. Cell Tissue Res 365:123-134

7. Hamilton CA, Young R, Jayaraman S, Sehgal A, Paxton E, Thomson S, Katzer F, Hope J, Innes E, Morrison LJ, Mabbott NA (2018) Development of in vitro enteroids derived from bovine small intestinal crypts. Vet Res 49:54

8. Stewart AS, Freund JM, Gonzalez LM (2018) Advanced three-dimensional culture of equine intestinal epithelial stem cells. Equine Vet J 50:241-248

9. Kozuka K, He Y, Koo-Mccoy S, Kumaraswamy P, Nie B, Shaw K, Chan P, Leadbetter M, He L, Lewis JG, Zhong Z, Charmot D, Balaa M, King AJ, Caldwell JS, Siegel M (2017) Development and characterization of a human and mouse intestinal epithelial cell monolayer platform. Stem Cell Rep 9:1976-1990

10. VanDussen KL, Marinshaw JM, Shaikh N, Miyoshi H, Moon C, Tarr PI, Ciorba MA, Stappenbeck TS (2015) Development of an enhanced human gastrointestinal epithelial culture system to facilitate patient-based assays. Gut 64:911-920
11. Moorefield EC, Blue RE, Quinney NL, Gentzsch M, Ding SL (2018) Generation of renewable mouse intestina epithelial cell monolayers and organoids for functional analyses. BMC Cell Biol 19:15

12. Thorne CA, Chen IW, Sanman LE, Cobb MH, Wu LF, Altschuler SJ (2018) Enteroid monolayers reveal an autonomous WNT and BMP circuit controlling intestinal epithelial growth and organization. Dev Cell 44:624-633. e624

13. van der Hee B, Loonen LMP, Taverne N, Taverne-Thiele JJ, Smidt H, Wells JM (2018) Optimized procedures for generating an enhanced, near physiological 2D culture system from porcine intestinal organoids. Stem Cell Res 28:165-171

14. Töpfer E, Pasotti A, Telopoulou A, Italiani P, Boraschi D, Ewart MA, Wilde C (2019) Bovine colon organoids: from 3D bioprinting to cryopreserved multi-well screening platforms. Toxicol In Vitro 61:104606

15. Zhao GH, Liu Y, Cheng YT, Zhao QS, Qiu X, Xu C, Xiao T, Zhu S, Liu GZ, Yin K (2018) Primary culture of cat intestinal epithelial cells in vitro and the cDNA library construction. Acta Parasitol 63:360-367

16. Acharya M, Arsi K, Donoghue AM, Liyanage R, Rath NC (2020) Production and characterization of avian crypt-villus enteroids and the effect of chemicals. BMC Vet Res 16:179

17. Bai S, Zhang K, Ding X, Wang J, Zeng Q, Peng H, Bai J, Xuan Y, Su Z, Wu $B$ (2019) Uptake of manganese from the manganese-lysine complex in primary chicken intestinal epithelial cells. Animals 9:559

18. Bar Shira E, Friedman A (2018) Innate immune functions of avian intestinal epithelial cells: response to bacterial stimuli and localization of responding cells in the developing avian digestive tract. PLoS One 13:e0200393

19. Derache $C$, Esnault E, Bonsergent $C$, Le Vern $Y$, Quéré $P$, Lalmanach $A C$ (2009) Differential modulation of beta-defensin gene expression by Salmonella Enteritidis in intestinal epithelial cells from resistant and susceptible chicken inbred lines. Dev Comp Immunol 33:959-966

20. Ghiselli F, Rossi B, Felici M, Parigi M, Tosi G, Fiorentini L, Massi P, Piva A, Grilli E (2021) Isolation, culture, and characterization of chicken intestinal epithelial cells. BMC Mol Cell Biol 22:12

21. Guo S, Liu D, Zhang B, Li Z, Li Y, Ding B, Guo Y (2017) Two Lactobacillus species inhibit the growth and a-toxin production of Clostridium perfringens and induced proinflammatory factors in chicken intestinal epithelial cells in vitro. Front Microbiol 8:2081

22. Li J, Li J Jr, Zhang SY, Li RX, Lin X, Mi YL, Zhang CQ (2018) Culture and characterization of chicken small intestinal crypts. Poult Sci 97:1536-1543

23. Lin X, Jiang S, Jiang Z, Zheng C, Gou Z (2016) Effects of equol on $\mathrm{H}_{2} \mathrm{O}_{2}$-induced oxidative stress in primary chicken intestinal epithelial cells. Poult Sci 95:1380-1386

24. Kaiser A, Willer T, Steinberg P, Rautenschlein S (2017) Establishment of an in vitro intestinal epithelial cell culture model of avian origin. Avian Dis 61:229-236

25. Nash TJ, Morris KM, Mabbott NA, Vervelde L (2021) Inside-out chicken enteroids with leukocyte component as a model to study host-pathogen interactions. Commun Biol 4:377

26. Pierzchalska M, Grabacka M, Michalik M, Zyla K, Pierzchalski P (2012) Prostaglandin E2 supports growth of chicken embryo intestinal organoids in Matrigel matrix. Biotechniques 52:307-315

27. Yuan C, He Q, Li JM, Azzam MM, Lu JJ, Zou XT (2015) Evaluation of embryonic age and the effects of different proteases on the isolation and primary culture of chicken intestinal epithelial cells in vitro. Anim Sci J 86:588-594

28. Geyra A, Uni Z, Sklan D (2001) Enterocyte dynamics and mucosal development in the posthatch chick. Poult Sci 80:776-782

29. Uni Z, Geyra A, Ben-Hur H, Sklan D (2000) Small intestinal development in the young chick: crypt formation and enterocyte proliferation and migration. Br Poult Sci 41:544-551

30. Zhang H, Li D, Liu L, Xu L, Zhu M, He X, Liu Y (2019) Cellular composition and differentiation signaling in chicken small intestinal epithelium. Animals 9:870

31. Alber A, Morris KM, Bryson KJ, Sutton KM, Monson MS, Chintoan-Uta C, Borowska D, Lamont SJ, Schouler C, Kaiser P, Stevens MP, Vervelde L 
(2019) Avian pathogenic Escherichia coli (APEC) strain-dependent immunomodulation of respiratory granulocytes and mononuclear phagocytes in CSF1R-reporter transgenic chickens. Front Immunol 10:3055

32. Borowska D, Kuo R, Bailey RA, Watson KA, Kaiser P, Vervelde L, Stevens MP (2019) Highly multiplexed quantitative PCR-based platform for evaluation of chicken immune responses. PLoS One 14:e0225658

33. Sutton KM, Hu T, Wu Z, Siklodi B, Vervelde L, Kaiser P (2015) The functions of the avian receptor activator of NF-KB ligand (RANKL) and its receptors, RANK and osteoprotegerin, are evolutionarily conserved. Dev Comp Immunol 51:170-184

34. Thomson CA, Nibbs RJ, McCoy KD, Mowat AM (2020) Immunological roles of intestinal mesenchymal cells. Immunology 160:313-324

35. Sun T, Norton D, Haycock JW, Ryan AJ, MacNeil S (2005) Development of a closed bioreactor system for culture of tissue-engineered skin at an air-liquid interface. Tissue Eng 11:1824-1831

36. Pinchuk IV, Mifflin RC, Saada JI, Powell DW (2010) Intestinal mesenchymal cells. Curr Gastroenterol Rep 12:310-318

37. Chen Y, Zhou W, Roh T, Estes MK, Kaplan DL (2017) In vitro enteroidderived three-dimensional tissue model of human small intestinal epithelium with innate immune responses. PLoS One 12:e0187880

38. Yin X, Farin HF, van Es JH, Clevers H, Langer R, Karp JM (2014) Nicheindependent high-purity cultures of Lgr5+ intestinal stem cells and their progeny. Nat Methods 11:106-112

39. Hofmann C, Obermeier F, Artinger M, Hausmann M, Falk W, Schoelmerich J, Rogler G, Grossmann J (2007) Cell-cell contacts prevent anoikis in primary human colonic epithelial cells. Gastroenterology 132:587-600

40. Watanabe K, Ueno M, Kamiya D, Nishiyama A, Matsumura M, Wataya T, Takahashi JB, Nishikawa S, Muguruma K, Sasai Y (2007) A ROCK inhibitor permits survival of dissociated human embryonic stem cells. Nat Biotechnol 25:681-686

41. Srinivasan B, Kolli AR, Esch MB, Abaci HE, Shuler ML, Hickman JJ (2015) TEER measurement techniques for in vitro barrier model systems. J Lab Autom 20:107-126

42. Placha I, Simonova MP, Cobanova K, Laukova A, Faix S (2010) Effect of Enterococcus faecium AL41 and Thymus vulgaris essential oil on small intestine integrity and antioxidative status of laying hens. Res Vet Sci 89:257-261

43. Pongkorpsakol P, Satianrapapong W, Wongkrasant P, Steinhagen PR, Tuangkijkul N, Pathomthongtaweechai N, Muanprasat C (2021) Establishment of intestinal epithelial cell monolayers and their use in calcium switch assay for assessment of intestinal tight junction assembly. Methods Mol Biol 2367:273-290

44. Olivier S, Leclerc J, Grenier A, Foretz M, Tamburini J, Viollet B (2019) AMPK activation promotes tight junction assembly in intestinal epithelial Caco-2 cells. Int J Mol Sci 20:5171

45. Bar-Shira E, Friedman A (2006) Development and adaptations of innate immunity in the gastrointestinal tract of the newly hatched chick. Dev Comp Immunol 30:930-941

46. Shira EB, Sklan D, Friedman A (2005) Impaired immune responses in broiler hatchling hindgut following delayed access to feed. Vet Immunol Immunopathol 105:33-45

47. Miao W, Wu X, Wang K, Wang W, Wang Y, Li Z, Liu J, Li L, Peng L (2016) Sodium butyrate promotes reassembly of tight junctions in Caco-2 monolayers involving inhibition of MLCKMMLC2 pathway and phosphorylation of PKC B2. Int J Mol Sci 17:1696

48. Yan H, Ajuwon KM (2017) Butyrate modifies intestinal barrier function in IPEC-J2 cells through a selective upregulation of tight junction proteins and activation of the Akt signaling pathway. PLoS One 12:e0179586

49. Li C, Ma D, Zhou H, Zhang M, An L, Wang Y, Wu C (2020) Effects of different doses lipopolysaccharides on the mucosal barrier in mouse intestine. Res Vet Sci 133:75-84
50. Chang Y, Yuan L, Liu J, Muhammad I, Cao C, Shi C, Zhang Y, Li R, Li C, Liu F (2020) Dihydromyricetin attenuates Escherichia coli lipopolysaccharideinduced ileum injury in chickens by inhibiting NLRP3 inflammasome and TLR4/NF-KB signalling pathway. Vet Res 51:72

51. Chen Y, Zhang H, Cheng Y, Li Y, Wen C, Zhou Y (2018) Dietary I-threonine supplementation attenuates lipopolysaccharide-induced inflammatory responses and intestinal barrier damage of broiler chickens at an early age. Br J Nutr 119:1254-1262

52. Bhatt AP, Gunasekara DB, Speer J, Reed MI, Peña AN, Midkiff BR, Magness ST, Bultman SJ, Allbritton NL, Redinbo MR (2018) Nonsteroidal antiinflammatory drug-induced leaky gut modeled using polarized monolayers of primary human intestinal epithelial cells. ACS Infect Dis 4:46-52

53. Moon C, VanDussen KL, Miyoshi H, StappenbeckTS (2014) Development of a primary mouse intestinal epithelial cell monolayer culture system to evaluate factors that modulate IgA transcytosis. Mucosal Immunol 7:818-828

54. Fang HW, Fang SB, Chiang Chiau JS, Yeung CY, Chan WT, Jiang CB, Cheng ML, Lee HC (2010) Inhibitory effects of Lactobacillus casei subsp. rhamnosus on Salmonella lipopolysaccharide-induced inflammation and epithelial barrier dysfunction in a co-culture model using Caco-2/peripheral blood mononuclear cells. J Med Microbiol 59:573-579

55. Kim HJ, Li H, Collins JJ, Ingber DE (2016) Contributions of microbiome and mechanical deformation to intestinal bacterial overgrowth and inflammation in a human gut-on-a-chip. Proc Natl Acad Sci USA 113:E7-15

56. de Jong HK, Parry CM, van der Poll T, Wiersinga WJ (2012) Host-pathogen interaction in invasive salmonellosis. PLoS Pathog 8:e1002933

57. Ugalde-Silva P, Gonzalez-Lugo O, Navarro-Garcia F (2016) Tight junction disruption induced by Type 3 secretion system effectors injected by enteropathogenic and enterohemorrhagic Escherichia coli. Front Cell Infect Microbiol 6:87

58. Alkie TN, Yitbarek A, Hodgins DC, Kulkarni RR, Taha-Abdelaziz K, Sharif S (2019) Development of innate immunity in chicken embryos and newly hatched chicks: a disease control perspective. Avian Pathol 48:288-310

59. Fasina YO, Holt PS, Moran ET, Moore RW, Conner DE, McKee SR (2008) Intestinal cytokine response of commercial source broiler chicks to Salmonella typhimurium infection. Poult Sci 87:1335-1346

60. Shaughnessy RG, Meade KG, Cahalane S, Allan B, Reiman C, Callanan JJ, O'Farrelly C (2009) Innate immune gene expression differentiates the early avian intestinal response between Salmonella and Campylobacter. Vet Immunol Immunopathol 132:191-198

61. Angrisano T, Pero R, Peluso S, Keller S, Sacchetti S, Bruni CB, Chiariotti L, Lembo F (2010) LPS-induced IL-8 activation in human intestinal epithelial cells is accompanied by specific histone $\mathrm{H} 3$ acetylation and methylation changes. BMC Microbiol 10:172

62. Abudabos AM, Alhouri HAA, Alhidary IA, Nassan MA, Swelum AA (2019) Ameliorative effect of Bacillus subtilis, Saccharomyces boulardii, oregano, and calcium montmorillonite on growth, intestinal histology, and blood metabolites on Salmonella-infected broiler chicken. Environ Sci Pollut Res Int 26:16274-16278

63. Grant A, Gay CG, Lillehoj HS (2018) Bacillus spp. as direct-fed microbial antibiotic alternatives to enhance growth, immunity, and gut health in poultry. Avian Pathol 47:339-351

\section{Publisher's Note}

Springer Nature remains neutral with regard to jurisdictional claims in published maps and institutional affiliations. 